NASA Technical Memorandum 102372

AIAA-89-2829

\title{
Design of a Thrust Stand for High Power Electric Propulsion Devices
}

Thomas W. Haag

Lewis Research Center

Cleveland, Ohio

Prepared for the

25th Joint Propulsion Conference

cosponsored by the AIAA, ASEE, ASME, and SAE

Monterey, California, July 10-14, 1989 
$-$ 


\title{
DESIGN OF A THRUST STAND FOR \\ HIGH POWER ELECTRIC PROPULSION DEVICES
}

\author{
Thomas W. Haag \\ National Aeronautics and Space Administration \\ Lewis Research Center \\ Cleveland, Ohio 44135
}

\section{ABSTRACT}

A thrust stand for use with high power clectric propulsion devices has been designed and tested. The thrust stand was specifically tailored to the needs of a 100 to $250 \mathrm{~kW}$ magnetoplasmadynamic (MPD) thruster program currently in progress at the NASA Lewis Research Center. The thrust stand structure was built as an inverted pendulum arrangement, supported at the base by water-cooled electrical power flexures. Thrust stand tares due to thruster discharge current were demonstrated to be negligible. Tares due to an applied field magnet current, after considerable effort, were reduced to less than 3.0 pereent of measured thrust. These tares, however, could be determined independently and subtracted from the indicated thrust measurement.

The paper gives a detailed description of the thrust stand design and operation with a $100 \mathrm{~kW}$ class MPD device. Other thrust stand tares due to vibration and thermal effects are discussed, along with issues of accuracy and repeatability.

\section{INTRODUCTION}

The high specific impulse of magnetoplasmadynamic (MPD) thrusters make them an attractive candidate for Earth-orbit transfer and planetary missions. Research programs throughout the 1960 's focused on boch pulsed and steady state propulsion systems.1,2 Slow progress with development of high power spacecraft electrical generating technology resulted in reductions of many government sponsored MPD thruster programs by the early 1970's. As space nuclear power concepts matured with the introduction of SP-100 in the carly 1980 's, interest in primary electric propulsion has increased.

With research activity expanding, there is a pressing need for high quality test facilities. In particular, accurate thrust measurements are essential if standards of comparison are to be maintained. Unfortunately, these measurements often become the first to be compromised by facility background effects. ${ }^{3}$ While they are frequently difficult to obtain, thrust measurements are one of the most important types of data in propulsion research.
A substantial effort to develop a radiation cooled MPD thruster was carried out by McDonnell Douglas in 1969.2 Thrust performance was obtained on steady-state applied field MPD devices at power levels from 14 to $41 \mathrm{~kW}$. Background pressures of $1.3 \mathrm{~Pa}\left(10^{-2}\right.$ lorr $)$ were maintained inside a $0.9 \mathrm{~m}$ diameter by $4 \mathrm{~m}$ long vacuum chamber. Thrust measurements were made using a single pendulum thrust stand suspended by stainless steel flexures. Electrical power for both the thruster and magnet were transferred to the $1.8 \mathrm{~m}$ long pendulum using mercury pots and coaxial buses. The thrust stand used water cooling to avoid thermal drift, however, a "thrust killer" device was needed to obtain a reliable zero point during operation. Deflection of the pendulum was measured by a linear displacement transducer, and calibrations were performed using a pulley and weight arrangement.

A complementary series of tests, using some of the same thruster hardware described above, was performed inside a $4.5 \mathrm{~m}$ diameter vacuum chamber at Lewis Research Center. ${ }^{4}$ In this case a short parallelogram-pendulum thrust stand was used in an attempt to verify the performance measured at McDonnell Douglas. Other features of the thrust stand were similar, including the use of coaxial mercury pots, weight and pulley calibration, and a thrust killer to determine zero drift. Good agreement was observed belween data oblained at the NASA facility and that reported from McDonncll Douglas.

In the early 1980's, the University of Stuttgart developed an extensive rescarch capability for high power MPD devices5. Highly regulated de power up to $6 \mathrm{MW}$ was made available. Performance measurements on a water cooled steady state MPD thruster were made at power levels up to $450 \mathrm{~kW}$. This was carricd out in a $2 \mathrm{~m}$ diameter by $5 \mathrm{~m}$ long test chamber, which could maintain a background pressure of $2.0 \mathrm{~Pa}$ $\left(1.5 \times 10^{-2}\right.$ torr) at an argon flow rate of $1.0 \mathrm{~g} / \mathrm{s}$. The MPD device was mounted 10 a platiorm and suspended by knife edge linkages. Thrusl was measured with a strain gage arrangement, and calibrated using free hanging weights. Mercury pots provided $7000 \mathrm{~A}$ of current transfer and cooling water was circulated onto the thrust stand through loops of nylon tubing. 
More recently, Princeton University has been conducting tests on self-ficld steady-state MPD thrusters. 6 A $1.5 \mathrm{~m}$ diameter by $6.4 \mathrm{~m}$ long steel vacuum tank was used which could maintain operational background pressures below $6.5 \times 10^{-2}$ $\mathrm{Pa}\left(5 \times 10^{-4}\right.$ torr). The thrust stand consisted of a $0.75 \mathrm{~m}$ pendulum suspended from stainless steel Mexurcs. Mercury pots transferred up to $1200 \mathrm{~A}$ to coaxial conductors in the pendulum arm, for a maximum power of $30 \mathrm{~kW}$. Deflection of the thrust stand was measured using strain gauges attached to an adjacent auxiliary flexure. Under normal conditions, the maximum uncertainty was less than 10 percent, however, this technique was found to be sensitive to electrical noisc. Backup deflection measurements were made using a mechanical dial gaugc, which was unaffected by electromagnetic activity.

This paper describes a new high power thrust stand that has been installed in an MPD thruster test facility. 7 It has been used to measure the performance of a water-cooled, applied field, stcady state MPD device at powers and currents up to $63 \mathrm{~kW}$ and $2500 \mathrm{~A}$, respectively. Typical thrust values of 1.5 newtons have been maintained for pcriods up to one hour. Future plans will require the thrust stand to operate at power levels up to $250 \mathrm{~kW}$.

The design objectives for the thrust stand are discussed as well as details of the actual hardware. Data obtained during hot thruster firings are presented which reveal the quality of test measurements performed. Commonly experienced problems, such as hysteresis, thermal drift, and magnetic interference are measured and discussed. A companion report (Ref. 8) contains an in depth performance analysis of the MPD thruster configurations tested in the facility.

\section{OPERATIONAL REOUIREMENTS}

The thrust stand was sized specifically for a $100 \mathrm{~kW}$ class MPD thruster. Propellants to be used include hydrogen, nitrogen, and argon. The vacuum facility intended for use could accommodate argon gas at a flow rate of about $10^{-4} \mathrm{~kg} / \mathrm{s}$ and still maintain a background pressure of $6.5 \times 10^{-2} \mathrm{~Pa}\left(5 \times 10^{-4}\right.$ torr $)$. Assuming a specific impulse of 2000 seconds, this would correspond to a thrust level of about $2 . \overline{0}$ newtons.

Electrical power was supplied to the MPD thruster by an arrangement of four $65 \mathrm{~kW}$ welding power supplies, providing a maximum current of $3000 \mathrm{~A}$ at $88 \mathrm{Vdc}$. The thrust stand was required to carry this current to the mounted thruster without inducing errors in thrust measurement. High current transfer was one of the most difficult design obstacles encountered due to the size of electrical conductors, as well as induced magnetic fields. While mercury filled pots have previously been utilized in such instances, concern about contamination of the test facility precluded their use for this work.

In addition to large currents, voltages as high as $1000 \mathrm{Vdc}$ were reached during routine thruster start-up. The high voltage was usually accompanied by a brief pulse of propellant to promote are ignition. As a consequence, all metal fittings which carried current had to be insulated to prevent arcing on surfaces other than the thruster electrodes.

The removal of heat from test hardware mounted on the thrust stand is a serious issue. Thruster anode losses as high as 90 percent of the input power are not uncommon. The MPD device intended for use in the facility was a water-cooled design, requiring a nominal flow of 40 liters per minute. Deionized water entered the thruster through a tubular cathode connection. The heated water was then discharged through a similar anode connection. This arrangement allowed copper tubes to serve as electrical conductors to and from the thruster. A means to transfer large water flow rates on and off the thrust stand was therefore needed.

An applied ficld magnet encircled the MPD thruster. Its purpose was to create a strong solcnoidal magnetic field within and external to the are discharge. Ficld strengths up 100.3 Tesla required that an independent $1500 \mathrm{~A}$ power supply be made available, with current transfer onto the thrust stand similar to that for the MPD discharge circuit. Resistive losses in the magnet resulted in heat generation up to $50 \mathrm{~kW}$, which had to be removed by passing cooling watcr through the magnet coils.

The mass of the MPD device combined with the applied field magnet was about $40 \mathrm{~kg}$, resulting in a thrust-to-weight ratio of approximately 0.005 . Under these circumstances inertial and gravitational effects can easily overshadow the relatively low propulsive force of the thruster. Facility pumping vibrations that are transfered to the thrust stand can seriously interfere with thrust measurements. If a rigidly mounted load cell were used to measure thrust, vibrational accelerations at an amplitude only 1 percent that of gravity would result in a signal to noise ratio of 0.5 . Similarly, an inadvertent tilt of only 0.1 degrecs from truc horizontal would result in a signal crror comparable to the full scale thrust. The vacuum facility test chamber was known to distort at least this amount when roughing from atmosphere to a hard vacuum.

The test section of the vacuum facility was a $3 \mathrm{~m}$ diameter by $3 \mathrm{~m}$ long extension to an $8 \mathrm{~m}$ 
diameter by $25 \mathrm{~m}$ long tank. A $3 \mathrm{~m}$ gate valve could isolate the main tank so that the test section could be vented to atmosphere independently. The thrust stand was required to be mounted on the retractable endcap of the test section in order for the MPD thruster to be accessible. This mobility requirement only complicated the delicate horizontal alignment and positioning sensitivity of the thrust stand. It was required to absorb the jolting force of endcap closure without damage and still retain its full degree of sensitivity.

\section{DESIGN APPROACH}

During the early stages of conceptual design, major concern focused on minimizing facility induced vibrations in the thrust signal and prevention of thermal drift. Because some vibration and thermal expansion was inevitable, one option was to ensure that deflection of the stand due to thrust was much larger than deflection due to other causes. If displacement errors due to vibration and local healing were on the order of a $0.1 \mathrm{~mm}$, a full scale thrust deflection of about $20 \mathrm{~mm}$ would make these errors insignificant.

A trade-off comparison was performed to determine what geometrical configuration could be most effective at permitting large displacements. Deflection of a frec hanging pendulum is determined strictly by the thrust-to-weight ratio $(\mathrm{T} / \mathrm{mg})$ of the suspended mass. Figure 1a represents a simplified schematic of such an arrangement where the deflection $D$ of a pendulum length $L$ can be determined by the equation:

$$
\mathrm{D}=\frac{\mathrm{T}}{\mathrm{mg}} \mathbf{L}
$$

With a $\mathrm{T} / \mathrm{mg}$ ratio of 0.005 , a pendulum deflection of $20 \mathrm{~mm}$ would require a radius length of $4 \mathrm{~m}$. This is larger than the test chamber itself and further, does not take into account the elastic restoring force of the flexures. An actual thrust stand would most likely include flexing members through which propellant, cooling water, and clectrical current would flow. The effective linear restoring force from all elastic members can bc combined and represented by a spring constant " $\mathrm{k}$ ". The simplified schematic in Figure $1 \mathrm{~b}$ illustrates a thruster of mass " $\mathrm{m}$ ", suspended by a pivoting link, and reacting against an elastic member. When the clastic flexure stiffness $k$ is introduced into eq(1) the deflection equation becomes:

$$
\mathrm{D}=\frac{\mathrm{T}}{\left(\mathrm{k}+\frac{\mathrm{mg}}{\mathrm{L}}\right)}
$$

The gravitational term is still retained but is now reenforced by an elastic term which further reduces thrust stand deflection. Even if flexure stiffness were zero, as in eq(1), displacement of a hanging pendulum design would still be laden by its suspended weight.

As an alternate design, an inverted pendulum was considered. As shown in Figure $1 c$, this arrangement differed in that the pivoting axis was located below the center of mass, rather than over it. Its deflection can be found simply by changing the sign of the weight term in eq(2) such that:

$$
\mathrm{D}=\frac{\mathrm{T}}{\left(\mathrm{k}-\frac{\mathrm{mg}}{\mathrm{L}}\right)}
$$

The sensitivity of this arrangement increases to the point of instability as the two terms in the denominator come close to cancelling each other. Optimization is achieved by tailoring the flexure stiffness to obtain the desired sensitivily and range of displacement.

A variation of this concept based on a parallelogram flexure arrangement was used with $1 \mathrm{~kW}$ class thrusters. 9 This type of design does not rotate back when displaced, but stays horizontal at all times. It would not be affected by changes to the thruster center of gravity, which could help prevent some types of measurement error. The structural arrangement in this type of design, however, is considerably more complicated. Four flexing joints would be required instead of one flexural axis with a pendulum. A simple inverted pendulum was therefore preferred because it was more sensitive and less complicated to build.

Due to MPD thruster water-cooling requirements and large conductors needed for high electrical currents, it was decided to use two 16 mm copper tubes as main flexures. The lubes had sufficient stiffness to support the mounted weight of the thruster, as well as providing the required displacement restoring force. They would be able to handle the cooling water flow rate and could conduct current to the thruster.

One way of improving the accuracy of thrust measurements is to constantly compare the measured force of the thruster with a known force of comparable magnitude. Since the thrust stand was normally enclosed in a vacuum facility, a remotely operated in-situ calibration system would be needed.

\section{THRUST STAND DESIGN}

An inverted pendulum type thrust stand design was selected for use in the facility. The MPD 
thruster and applied field magnet were mounted on a movable platform which was, in turn, supported by an upright flexure arrangement. The platform could deflect horizontally from its neutral position up to $50 \mathrm{~mm}$ with an applied thrust of about 5 newtons. This large range of travel was specifically chosen to minimize effects of facility vibration and thermal strain.

The complete thrust stand was comprised of three major sections. (Figures 2, 3) They include a lower frame, a pivoting structure, and a reference structure.

The lower frame was a large "A" shaped assembly which laid flat at the bottom of the thrust stand. It was constructed from $1.4 \mathrm{~m}$ long by 50 $\mathrm{cm}$ wide stainless steel bars that had been bolted logether. It contained a screw driven elevating mechanism at the apex of the frame and a gravity inclinometer which were both operated from a facility instrumentation rack. Remote control leveling of the thrust stand to a resolution of 10 seconds of arc was possible. This capablity proved to be very useful in compensating for facility distortions during pumpdown.

The pivoling structure of the thrust stand was fabricated mostly of aluminum angle and channel. It transferred the weight of the thruster to a system of flexures anchored to the lower frame. A $12 \mathrm{~mm}$ thick aluminum mounting platc was placed at the top of the pivoting structure, to which the MPD thruster and applied field magnet were bolted. All current carrying conductors were fed through bakelite insulators on the mounting plate using bulkhead tube fittings. The top mounting surface was protected from plume heat with mica and kapton sheets, as well as reflective mylar. The flexures were configured such that all movement was restricted except for pivoting rotation about an axis $150 \mathrm{~cm}$ below the thruster center. The primary flexures consisted of two 16 $\mathrm{mm}$ O.D. copper tubes $60 \mathrm{~cm}$ long, with a wall thickness of $1.1 \mathrm{~mm}$. These tubes not only supported the entire weight of the pivoting structure, but also conducted the thruster discharge current of $3000 \mathrm{~A}$ and cooling water flow of 40 liters per minute. Electrical current to the applied field magnet was transferred by a total of four 9 $\mathrm{mm}$ O.D. copper tubes paired in parallel for both supply and return. An "S" shaped bend was placed in each tube to allow for axial expansion, thus avoiding interference with the primary flexures. Gascous propellant was transferred by a single 6 $\mathrm{mm}$ O.D. stainless steel tubc. A 22 lead flexible linkage transferred thruster instrumentation signals. All of the flexures were designed to operate within their elastic limit and were, in tum, the source of the thrust stand restoring force. Due to a lack of friction, motion damping was obtained through the use of a derivative feedback loop. The thrust stand displacement signal was sent through a series of operational amplifiers, which took the time derivative of position in order to obtain an instantaneous velocily signal. This signal was amplified and used to drive a linear actuator in a direction to oppose platform molion. The system was active only during brief perturbations and did not affect steady state thrust measurements.

The reference structure was mounted rigidly to the lower frame and was located immediately behind the pivoting structure. Diagonal braces ran from its highest point down to the apex of the lower frame, allowing no forward or backward movement. Thrust data were oblained by means of displacement measurements, using a linear variable differential transformer located within the reference structure. The transformer's freely moving magnetic core was linked to the thruster mounting platform by an extension rod, enabling thrust induced deflections to be measured. The differential transformer provided frictionless measurement of up to $50 \mathrm{~mm}$ with a detectable resolution of $0.003 \mathrm{~mm}$. An electronic readout in the facility instrument rack digitally displayed the displacement. An analog oulput signal was sent to the feedback damping controller and a data chart recorder.

A remotely operated mechanism to allow insitu thrust calibration was mounted to the back of the reference structure. Threc $50 \mathrm{~g}$ brass weights were spaced at $20 \mathrm{~cm}$ intervals along a monofilament nylon line. The top end of the line was strung over a precision pully and attached to a rod on the thruster mounting platform. An electric motor unwound the other end of the line to engage each weight in succession. If the motor continued to rotate past the fully wound position a lock up lever was activated which forced the pivoting structure against its forward stops. This prevented platform movement and protected the thrust sland from damage whenever measurements were not being take.

\section{THRUST STAND OPERATION}

\section{Calibration Results}

Results of a calibration sequence are shown are Figure 4. The analog thrust signal was input to a strip chart recorder, whose trace is shown in the figure. The calibration was performed inside the test facility under full vacuum, with cooling water circulating through both the thruster and applicd field magnet. The trace begins with a zero reference and was followed by a series of steps with the addition of cach calibration weight. The first three steps result from thrust stand deflections under a load of $50.21 \mathrm{~g}, 100.89 \mathrm{~g}$, and $151.74 \mathrm{~g}$, respectively. Weights are off loaded in reverse order and would ideally present a mirror 
image of the upward trace. Slight offsets in opposing steps reveal hysteresis, which can be attributed to frictional effect or plastic deformation of nexures. As can be seen in figure 4, hysteresis in the thrust stand movement is quite small, and incremental displacements from each additional weight are virtually identical. Mechanical pumping vibrations have little visible effect on the signal trace, although transients were usually seen when cooling water pumps were turned on or off. By analyzing calibration results, it has been determined that uncertainty in thrust measurements due to nonlinearity and hysteresis are only a fraction of one percent, full scale.

\section{Facility Effects}

Due to the low thrust-to-weight ratio of thrusters expected to be used in the facility, thrust measurements will be very sensitive to angular tilting of the thrust stand. To make the situation worsc, the $3 \mathrm{~m}$ diameter test section of the vacuum facility distorts under atmospheric pressure loads during every pumpdown. Figure 5 illustrates the effect of these distortions on the thrust stand when vacuum chamber pumpdown occurs. The thrust trace begins with a calibration sequence at atmosphere and is followed shortly afterward by activation of the test section vacuum pump. Within 15 minutes the test section was at rough vacuum and a very large shift in reference zero had occurred. An inclinometer mounted in the thrust stand base measured a change in slope of 0.10 degrecs during the pump down. A remotely controlled elevating motor was normally used to correct for such deviations, whether they were caused by facility stress or thermal expansion. This leveling capability has proven to be very useful in selecting and maintaining a stable reference zero from which to operate.

\section{Discharge Current Effects}

A series of tests were carried out to determine the effect of high electrical currents on thrust measurements. The purpose was to measure electromagnetic forces which could cause errors in thrust measurements. A tubular shunt was put across the thruster discharge power conductors just bchind the thruster itself. This shorted the thruster voltage but still allowed electrical current and cooling water to flow. The main discharge power supply was then varied from 200 to $3000 \mathrm{~A}$ dc. As can be seen in Figure 6, initial thrust stand tares were quite high and appeared to be quadratic with current. This squared relation indicates that the conductors were reacting against each other.

After a review of the facility layout, altention was focused on possible sources of stray magnetic fields. The welding power supplies, located in the building basement, were used to feed two overhead cable trays. The trays ran parallel and were spaced about $2 \mathrm{~m}$ apart. As originally configured, all positive cables were placed in one tray, and all negative cables in the other. This arrangement was used for both the thruster discharge cables and applied field magnet cables. The original reason for scparate trays was to decrease the likelihood of arcing and to ease concern about repulsive magnetic forces between dissimilar cables. A comparable situation existed on the thrust stand where opposite polarities were separated by about $0.5 \mathrm{~m}$.

When electrical current was sent through the facility power circuit, it was found that a large and complex field structure was cstablished. The magnetic fields on the thrust stand had apparently formed a coupling moment with fields which surrounded the racility. This conclusion was confirmed by a series of tests in which electrical connections on the welding power supplies and the thrust stand were reversed in a number of different combinations.

Elimination of magnetically induced tares required extensive revisions to both the thrust stand and the facility power distribution cabling. An ideal solution would have been to use coaxial power buses routed continuously from the welding power supplies to the thruster. The magnetic field produced in the center conductor would be cancelled by the field produced by the outer conductor, and no external influence would be present. The problem with a coaxial arrangement, however, is that it would be very difficult to construct. Coaxial cable suitable for 3000 A would undoubtedly require special manufacturing and cause a long delay with installation. The thrust stand would require coaxial current flexures, and water cooling of the conductors would have been more complicated. Instead, it was decided to pair all conductors of opposite polarity as close logether as possible. The magnelic cancelling effect would be similar to that of coaxial conductors, except for a lateral offset of one cable width. Since magnetic flux intensity varies inversely with distance, this width of about $3 \mathrm{~cm}$ when viewed from a meter away would appear small, and magnetic fields would effectively cancel. The benefit of this reduction would be compounded once again if it were incorporated into both the facility cable layout and that of the thrust stand.

Modification of the test facility was carried out in two parts. This began with changes to power cabling running from the welding supplies to the vacuum feed-throughs, and was followed by changes to the thrust stand itself. The practice of using separate overhead trays for positive and negative cables was discontinued. Cables were reassigned to establish a balanced current flow in each tray. Intermingling of opposite polarities was 
carricd out wherever it was practical, to leave the smallest possible residual magnetic field. Electrical feed-throughs into the tank were also aliernated to distribute current flow more evenly.

The thrust stand was removed from the test facility and modified in a similar way. The previous design used two primary flexures as positive and negative conductors, spaced about 0.5 m apart. The revised design added two new flexures which were located about $40 \mathrm{~mm}$ adjacent to the originals. These would be used to conduct the anode current, while the two original flexures were reconfigured to conduct the cathode current. Care was taken to route opposing conductors as close together as possible all the way to the thruster.

As can be secn by comparing both curves of Figure 6, magnetic thrust tares for the revised thrust stand configuration are considerably less than those of the original arrangement. By moving current carrying conductors of opposite polarity closer together, magnetically induced tares were not completely eliminated, but were reducted to only about 6 percent of their original value. Thrust tares at a discharge current of 2500 A presently amount to 20 millinewtons, which represents approximately 1 percent of a typical thrust measurement value.

\section{Applied Field Effects}

Thrust tares induced by the applied field magnet have been pursued using the same method as was used for the thruster discharge current. The lower curve in Figure 7 was obtained by installing a tubular shunt across the conductors just in front of the magnet, which was disconnected but still mounted in place. Tares due to the applied ficld current conductors are quite small and represent only about 4 millinewtons of error at maximum current.

When the shunt was removed and the magnet operated normally, thrust tares were much higher. The upper curve of Figure 7 shows a magnetically induced force of 72 millinewtons at an applied field current of $1450 \mathrm{~A}$. Because the current conductors contribute very litte to this force, it is unlikely that further thrust stand improvements will result in any additional reduction of applied field tares.

Since the sole purpose of an applied field magnet is to generate a large and powerful field, magnetic interaction with the rest of the facility was inevitable. Possible corrective measures to be considered include elimination of all magnetic metals from the facility, or redesign of the magnet itself to better confine flux within the area of need.

Under present conditions, the maximum applied field tare contributes less than 4 percent of measured thrust during a typical test firing. Due to their independent nature, it is reasonable to assume that existing applied field tares can be subtracted out of performance data without adversely affecting its accuracy.

\section{Use with MPD Thrusier}

Thrust measurements obtained during typical MPD thruster operation are shown in Figure 8 . The thruster was run at a power level of $37 \mathrm{~kW}$ for a period of 30 minutes. Data recording began with an initial calibration sequence in which three 50 gram weights were lowered and raised. Once a thrust reference zero was established, argon propellant began to flow at a presel rate. The first step increase measured after calibration (Figure 8) represents cold gas thrust. Approximately 50 seconds later the applied ficld magnet was turned on, resulting in a slight step increase in measured thrust. The applied field tare could be measured at this point and subtracted from subsequent data. About one minute Iater the MPD are was ignited, resulting in a very abrupt thrust increase. The thrust stand would normally take about 5 scconds to equilibrate after the initial surge, however, the start shown in Figure 8 was particularly rough.

Thirty minutes of steady operation followed in which discharge voltage and thrust wandered slightly as time progressed. The thrust stand inclinometer indicated a slow rate of angular shift, presumably duc to thermal expansion of the facility structure. The tilting was periodically corrected using a remotely operated leveling motor.

Arc termination was accompanied by an immediate drop in thrust. The applied field magnet was turned off one minule after the arc was extinguished, followed one minute later by the propellant flow. The residual thrust indication following propellant shut off represents a drift error of about 1.8 percent. While this offset frequently occured during extended test runs, its cause has not yet been detemined. Thermocouples which had been placed at various locations on the thrust stand indicated no unusually high surface temperatures. The only noticeable warming occurred in the vicinity of flexure tubes, which convect cooling water down from the thruster. While the issue of zero offset has not yet been fully understood, subtraction of the drift from thrust measurements would be a conservative approach until it can be completely solved.

The last event which occurred in Figure 8 was a sccond calibration sequence. Aside from a zero offset, the calibration trace appears identical to the one performed prior to the thruster firing. This would indicate that no obscrvable change in sensitivity had occurred and that thrust measurements which were made are reasonably accurate. 


\section{CONCLUDING REMARKS}

A thrust stand for use with 100 to $250 \mathrm{~kW}$ steady state MPD thrusters has been built and tested successfully. The stand was based on an inverted pendulum configuration which resulted in large displacements and a high degree of resolution. Up to $50 \mathrm{~mm}$ of deflection was observed under a force of 5 newtons. This large range of displacement significantly reduced the effects of facility induced vibrations on thrust measurements.

A remotely operated system was provided for in-situ calibration of the thrust stand prior to and immediately after data were obtained. Calibrations showed that thrust measurements were linear and repeatable to within a fraction of one percent.

Structural distortions of the vacuum facility due to pumpdown were detected with an inclinometer located in the thrust stand base. Slope deviations as small as 10 seconds of arc could be compensated using a remote controlled leveling motor.

Early problems with magnetically induced tares were reduced by rerouting high current cables and reducing stray fields. Tares due to discharge and applied field currents were brought down to 26 millinewtons at $3000 \mathrm{~A}$ and 63 millinewtons at $1400 \mathrm{~A}$, respectively. This represents the upper limit of the present power supply capability, and therefore the largest tares likely to occur.

The thrust stand was used with a water cooled applied field steady state MPD device at a power level up to $63 \mathrm{~kW}$. Hot thruster firings as long as 1 hour were performed. By precisely maintaining a level thrust stand base, thermal drift could be held to about 2 percent of the full scale reading. The remaining thermal drift and tares caused by the applied magnetic field could be subtracted from the thrust measurement to further reduce systematic error. By subtracting tabulated discharge current magnetic tares, uncertainty in thrust measurement could be reduced to approximatcly 2 percent of the measured value.

\section{REFERENCES}

1. Jarrett, O., Hoell, J. M., and Lockwood, D. L., "Thrust Measurements on a Pulsed VacuumArc Thruster," AIAA Paper 70-1146, September 1970.
2. Esker, D. W., Checkley, R. J., and Kroutil, J. C., "Radiation Cooled MPD Arc Thruster," MDCH296, McDonnell-Douglas Corp., St. Louis, MO, July 1969, NASA CR-72557.

3. Sovie, R. J., and Connolly, D. J., "Effect of Background Pressurc on Magnetoplasmadynamic Thruster Operation," Journal of Spacecraft and Rockets, Vol. 7, No. 3, March 1970 , pp. 255-258.

4. Connolly, D. J,, and Sovic, R. J., "Performance of Radiation-Cooled Magnetoplasmadynamic Arc Thrusters," NASA TM X-1908, October 1969.

5. Kurtz, H. L., Auweter-Kurtz, M., and Schrade, H. O., "Self Field MPD Thruster Design Experimental and Theoretical Investigations," AIAA Paper 85-2002, September 1985.

6. Myers, R. M., "Encrgy Deposition in Low Power Coaxial Plasma Thrusters," PhD Thesis, Princeton University, June 1989.

7. Sovey, J, S., Mantenicks, M. A., Haag, T. W., Raitano, P., and Parks, J. E., "Test Facility and Preliminary Performance of a $100 \mathrm{~kW}$ Class MPD Thruster," NASA TM102021, May 1989.

8. Mantenieks, M. A., Sovey, J. S., Myers, R. M, Haag, T. W., Railano, P., Parks, J. E., "Performance of a $100 \mathrm{~kW}$ Class Applied Field MPD Thruster," AIAA paper 89-2710, July 1989.

9. Haag, T. W., "Arcjet Starting Reliability: A Multistart Test on Hydrogen/Nitrogen Mixtures," AIAA Paper 87-1061, May 1987, NASA TM89867, May 1987. 


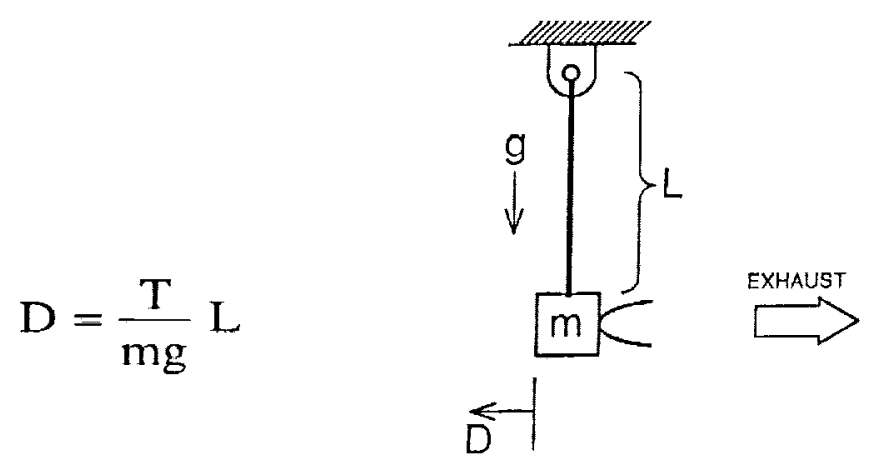

FIGURE Ia. - SCHEMATIC OF FREE HANGING THRUST STAND.

$\mathrm{D}=\frac{\mathrm{T}}{\left(\mathrm{k}+\frac{\mathrm{mg}}{\mathrm{L}}\right)}$

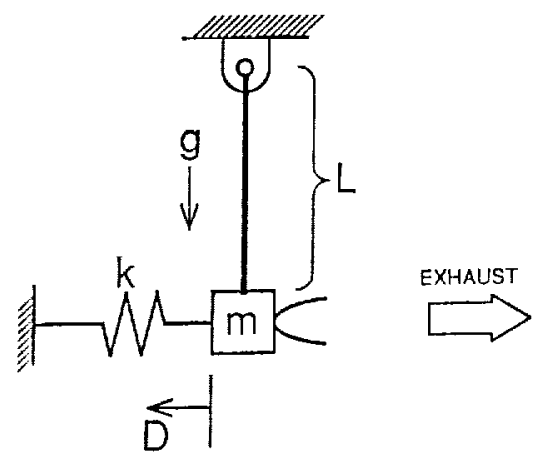

FIGURE ib. - SCHEMATIC OF FLEXURAL THRUST STAND.

$\mathrm{D}=\frac{\mathrm{T}}{\left(\mathrm{k}-\frac{\mathrm{mg}}{\mathrm{L}}\right)}$

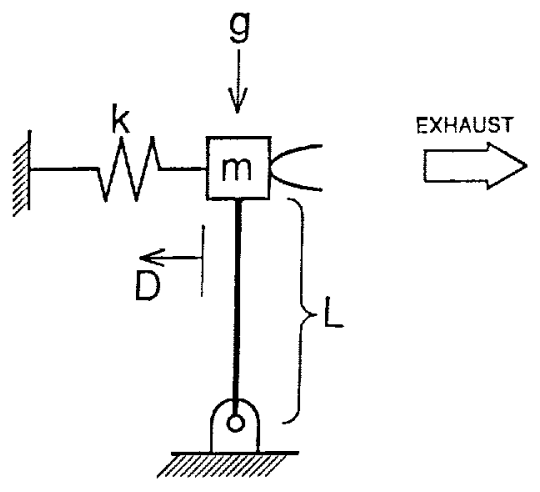

FIGURE IC. - SCHEMATIC OF INVERTED THRUST STAND.

8 


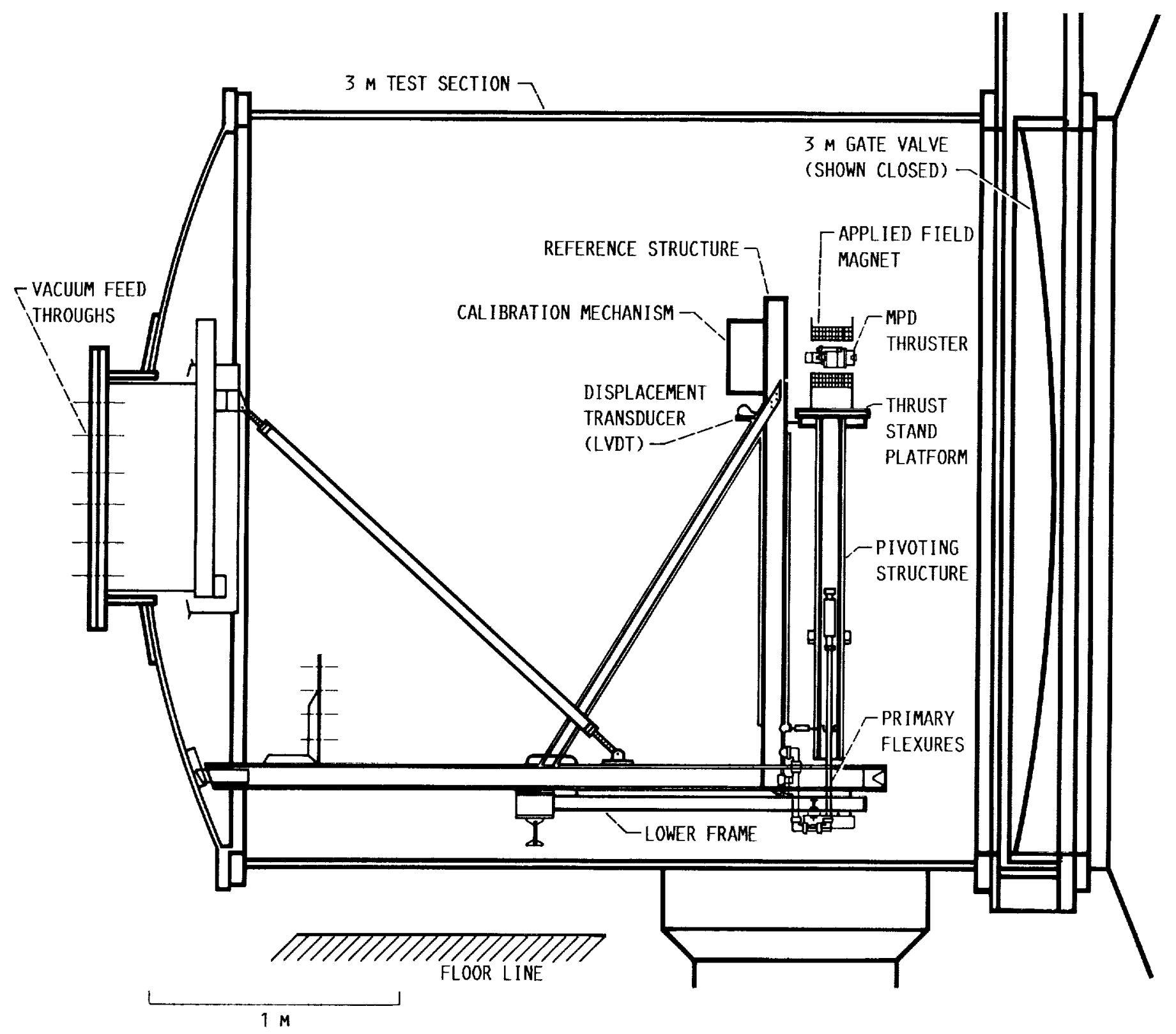

FIGURE 2. - SCHEMATIC OF MPD THRUST STAND INSTALLATION. 


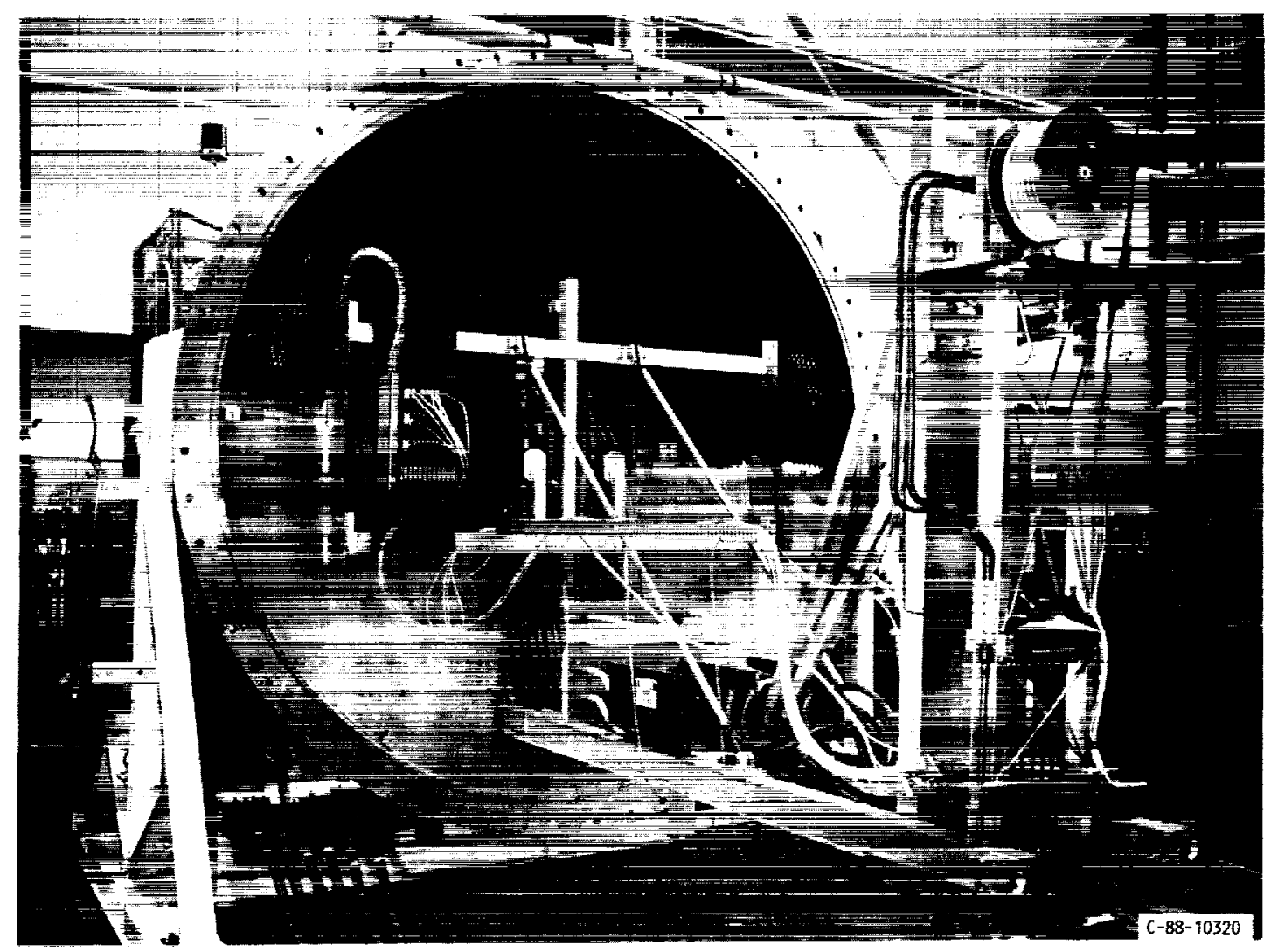

FIGURE 3a. - FRONT VIEW OF THRUST STAND MOUNTED ON 3M ENDCAP.

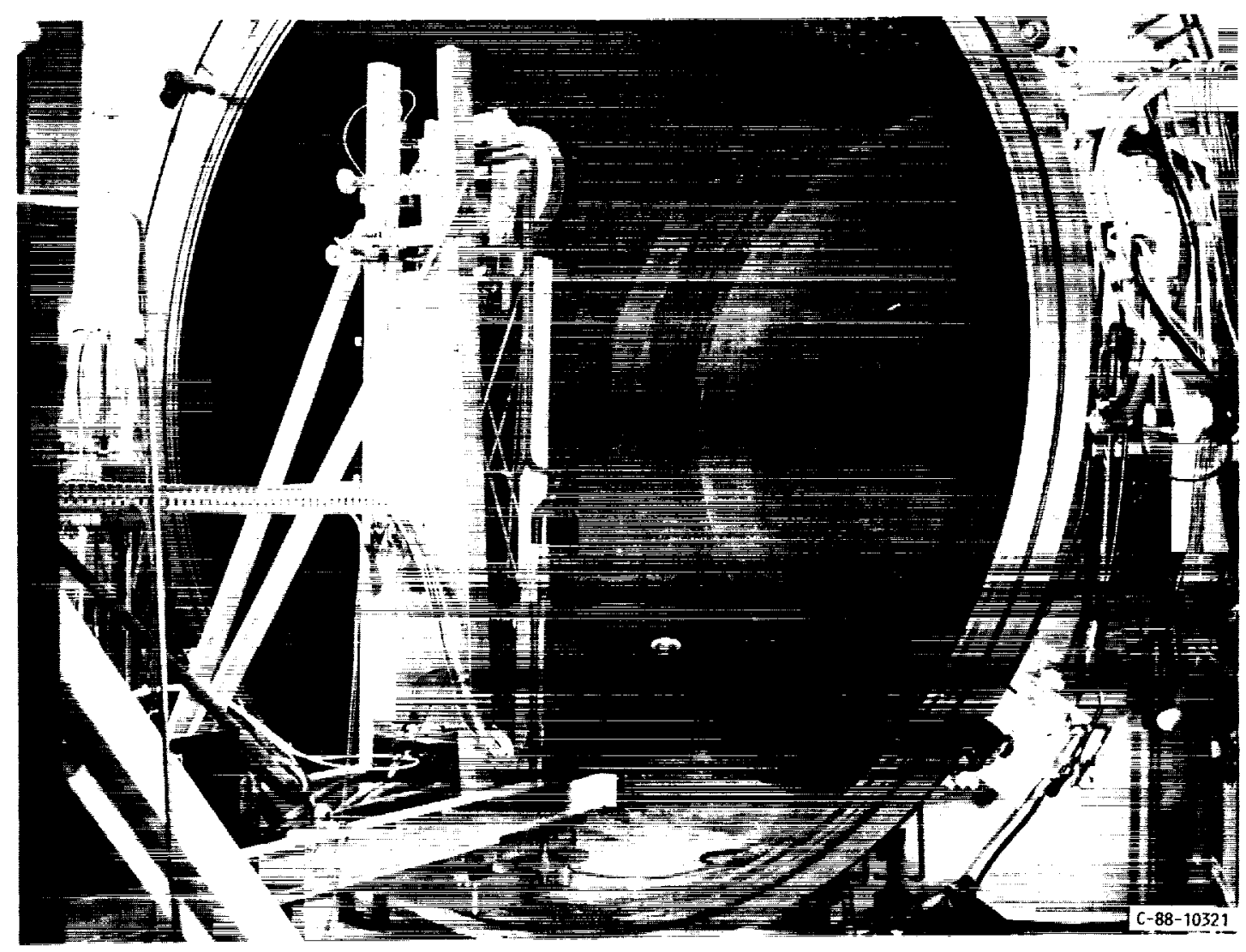

FIGURE 3b. - BACK VIEW OF THRUST STAND BEING ROLLED INTO 3M TEST SECTION. 


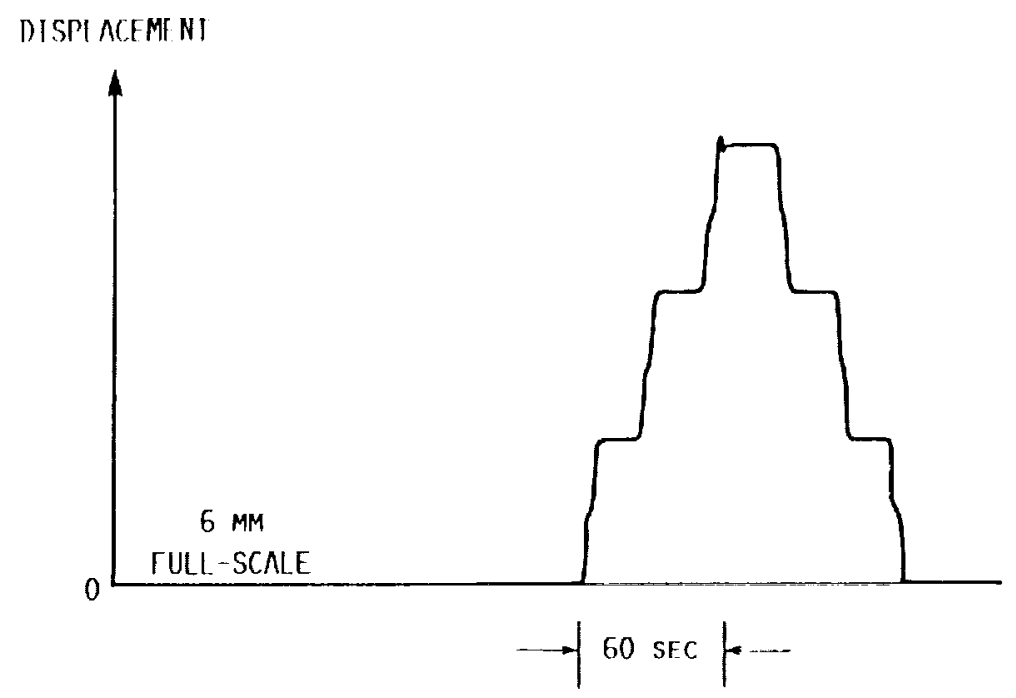

FIGURE 4. - THRUST STAND DISPLACEMENT DURING CALBRATION SEQUFNCE.

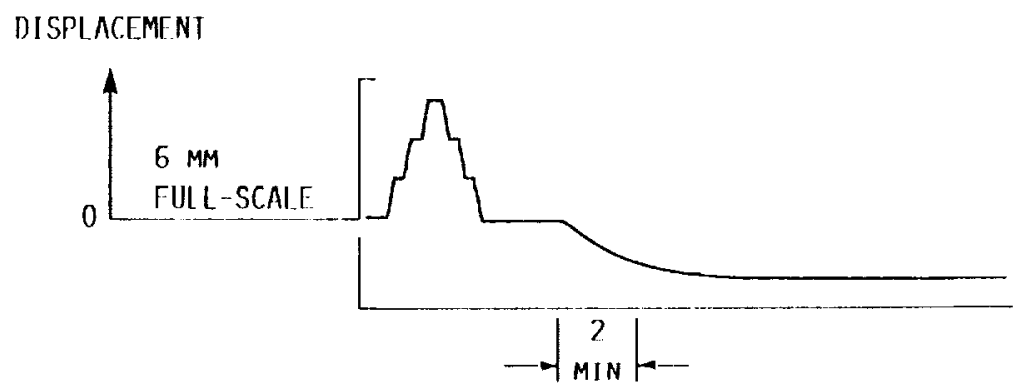

FIGURE 5. - THRUST STAND DISPLACEMENT DIIRING FACILITY PIMP DOWN. 


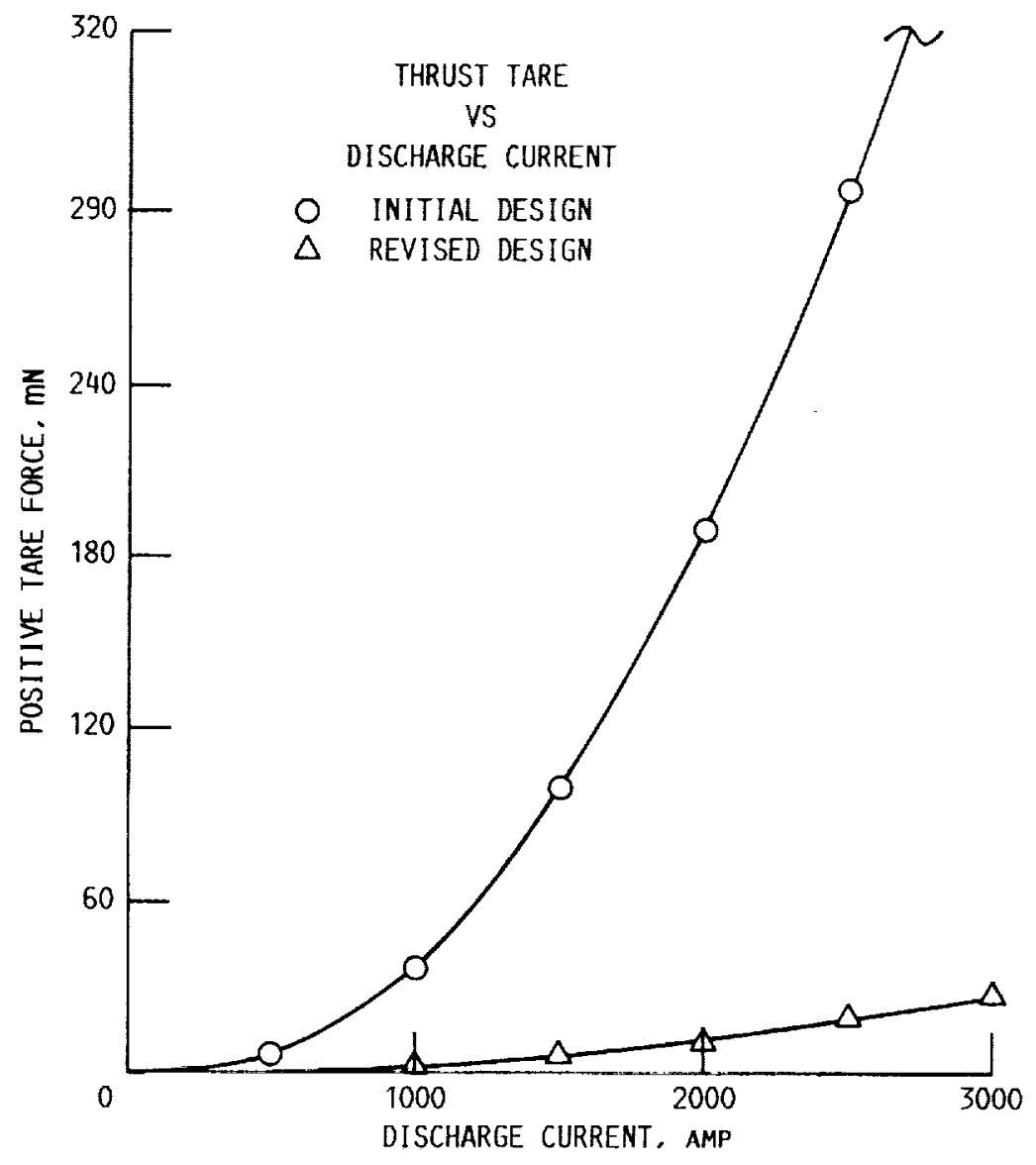

FIGURE 6. - THRUST TARES CAUSED BY DISCHARGE CURRENT.

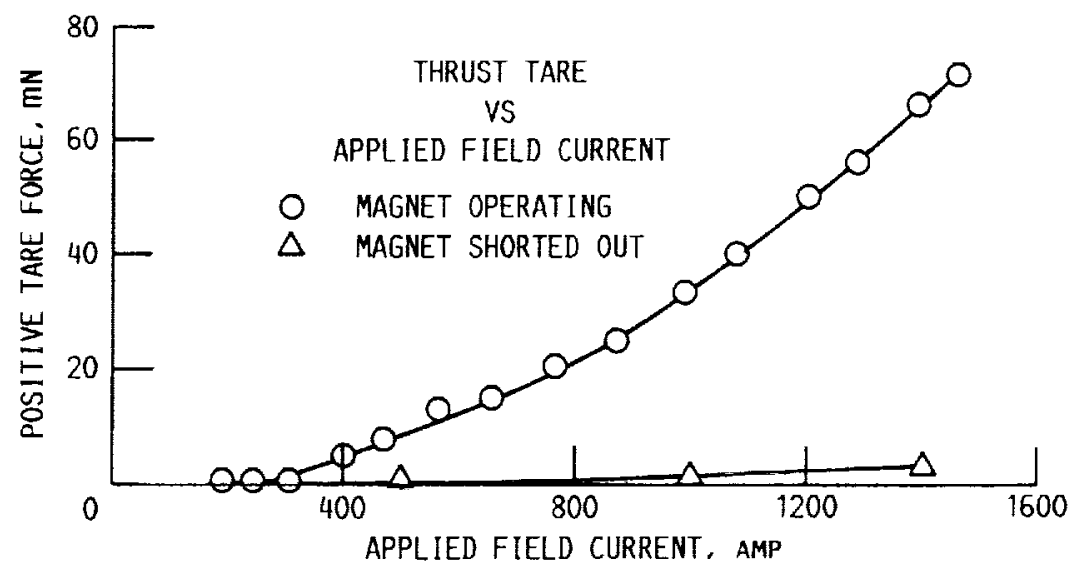

FIGURE 7. - THRUST TARES CAUSED BY APPLIED FIELD CURRENT. 


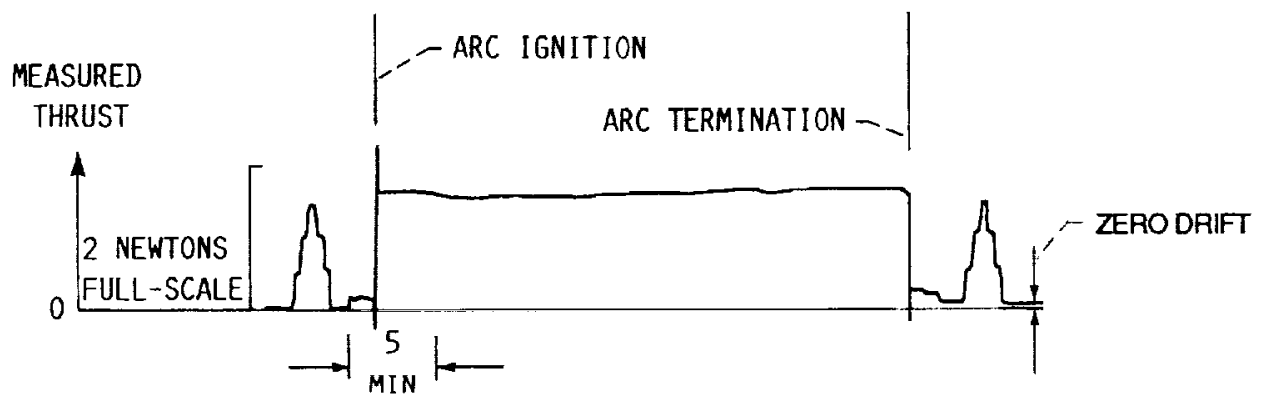

FIGURE 8. - THRUST MEASUREMENTS DURING ACTUAL MPD THRUSTER TEST. 


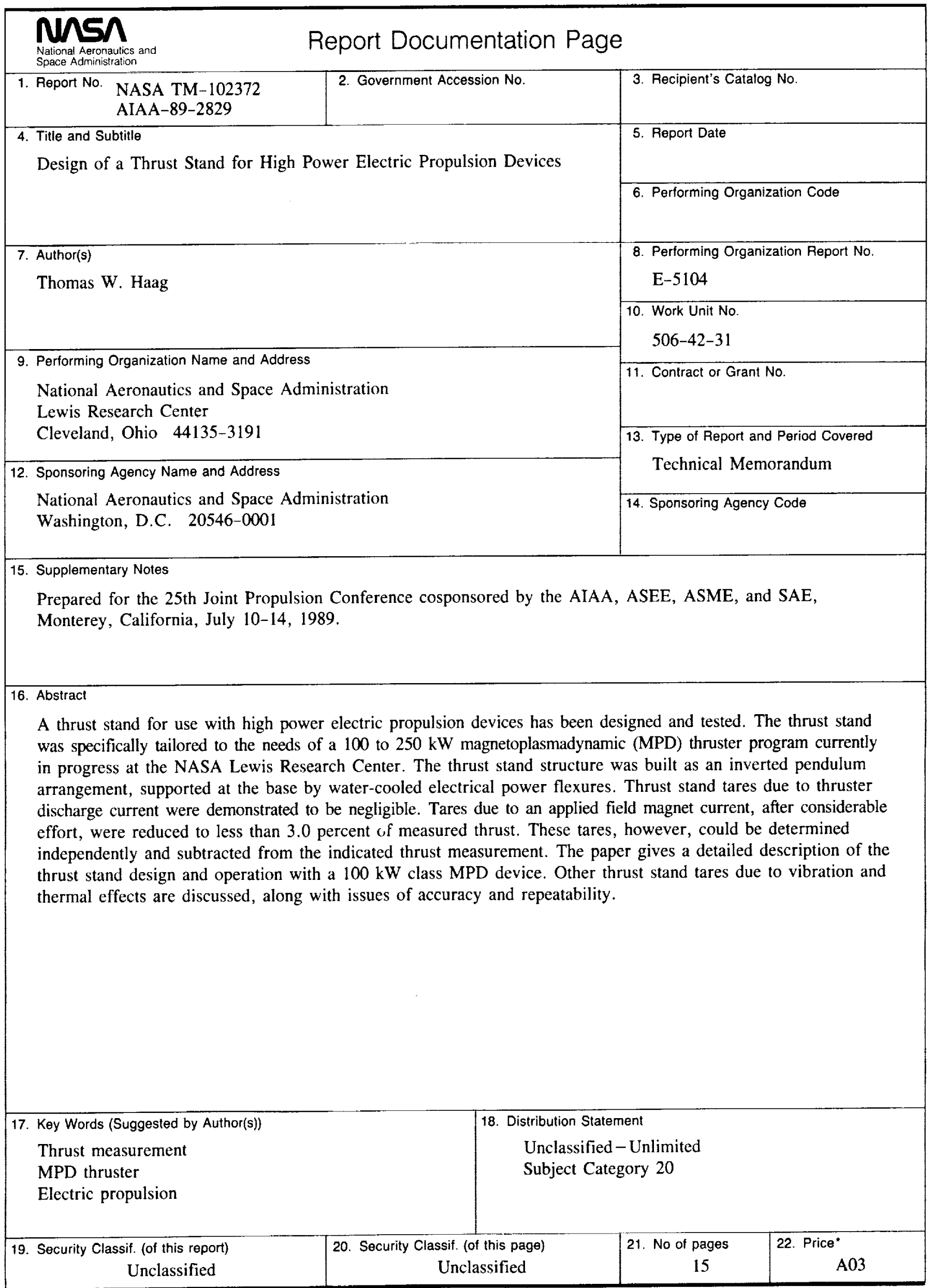

